\title{
KEFEKTIFAN MODEL TIPE MAKE A MATCH TERHADAP HASIL BELAJAR MATEMATIKA
}

\author{
Rizky Dwi Destari ${ }^{1}$, Sukamto $^{2}$ \\ 1,2Jurusan Pendidikan Guru Sekolah Dasar, FP \\ Universitas PGRI Semarang \\ Semarang, Indonesia \\ email : Rizkydwidest@gmail.com
}

\begin{abstract}
Abstrak
Penelitian ini bertujuan untuk mengetahui signifikan hasil belajar Matematika melalui model pembelajaran Make a Match pada kelas II SD Islam AI Fattah Semarang. Jenis penelitian ini bersifat PreExperimental Design dengan bentuk desain eksperimen yang digunakan adalah One-Group PretestPosttest Design. Populasi yang digunakan pada penelitian ini yaitu seluruh kelas II SD Islam Al Fattah Semarang. Sampel yang digunakan adalah siswa kelas II SD Islam Al Fattah Semarang yang diambil dengan teknik Random Sampling. Metode pengumpulan data adalah tes dan observasi secara langsung. Teknik analisis yang digunakan adalah uji-t. Berdasarkan hasil analisis $t_{\text {hitung }} 3,876>t_{\text {tabel }} 2,093$. $H_{a}$ diterima artinya model pembelajaran Make a match efektif terhadap hasil belajar Matematika kelas II SD Islam Al Fattah Semarang.
\end{abstract}

Kata kunci: Model Make A Match, Hasil Belajar

\begin{abstract}
This study aimed to determine the significance of Mathematics learning outcomes through the Make a Match learning model in class II of Al Fattah Islamic Elementary School Semarang. This type of research was Pre-Experimental Design with the form of experimental design used was One-Group Pretest-Posttest Design. The population used in this study were all class II Al Fattah Islamic Elementary School Semarang. The sample used was class II AI Fattah Islamic Elementary School Semarang, which was taken by Random Sampling technique. The method of collecting data was a test and direct observation. The analysis technique used was the t-test. Based on the results of the analysis $t_{\text {hitung }} 3,876>$ $t_{\text {tabel }}$ 2.093. $H_{a}$ accepted means that the Make a match learning model was effective against the Mathematics learning outcomes in class II of Al Fattah Islamic Elementary School Semarang.
\end{abstract}

Keywords: Make A Match Model, Learning Outcomes 


\section{Pendahuluan}

Berdasarkan Undang-Undang Republik Indonesia Nomor 20 Tahun 2003 Bab 1 Pasal 1 No. 1 tentang pendidikan nasional yang berbunyi:

"Pendidikan adalah usaha sadar dan terencana untuk mewujudkan suasana belajar dan proses pembelajaran agar peserta didik secara aktif mengembangkan potensi dirinya untuk memiliki kekuatan spiritual, keagamaan, pengendalian diri, kepribadian, kecerdasan dan akhlak mulia, serta keterampilan yang diperlukan dirinya, masyarakat, bangsa dan negara."

Pembelajaran pada hakekatnya tidak hanya sekedar menyampaikan pesan pembelajaran kepada siswa, akan tetapi merupakan aktifitas profesional yang menuntut guru untuk dapat menggunakan keterampilan dasar mengajar secara terpadu, serta menciptakan situasi dan kondisi yang memungkinkan siswa dapat belajar secara efektif dan efisien. Pembelajaran di sekolah dasar meliputi beberapa mata pelajaran diantaranya Pendidikan Agama, Pendidikan Kewarganegaraan, Bahasa Indonesia, Matematika, IImu Pengetahuan Alam, Ilmu Pengetahuan Sosial, Seni Budaya dan Prakarya, serta Pendidikan Jasmani, Olahraga dan Kesehatan. Menurut Aliputri (2018) Pendidikan dan pengajaran adalah suatu proses yang sadar tujuan. Tujuan dapat diartikan sebagai suatu usaha untuk memberikan rumusan hasil yang di harapkan siswa setelah melaksanakan pengalaman belajar. Pengalaman belajar bisa didapatkan dimana saja, salah satunya di sekolah. Menurut Muslimah (2018) Keberhasilan suatu proses pembelajaran salah satunya ditentukan oleh peran guru dalam mengembangkan metode yang digunakan. Peran guru dalam hal ini adalah bagaimana kreatifitas guru dalam mendesain proses belajar mengajar yang efektif, yaitu proses belajar yang mengembangkan metode dengan penekanan pada partisipasi dan keaktifan siswa di kelas.

Matematika berasal dari akar kata mathema artinya pengetahuan, mathanein artinya berpikir atau belajar. Dalam kamus Bahasa Indonesia diartikan matematika adalah ilmu tentang bilangan hubungan antara bilangan dan prosedur oprasional yang digunakan dalam penyelesaian masalah mengenai bilangan (Depdiknas). Ali Hamzah dan Muhlisrarini (2014: 51) matematika sebagai alat untuk menyelesaikan masalah dengan menerjemahkan masalahmasalah ke dalam simbol-simbol matematika. Mata pelajaran matematika dirasa sangat sulit oleh para peserta didik dikarenakan banyaknya rumus-rumus yang harus dikuasai oleh seorang siswa dalam mempelajari setiap cabang matematika pada saat yang sama, siswa juga harus menguasai rumus-rumus sebelumnya sehingga tidak heran jika banyak siswa yang mengeluh ketika belajar matematika.

Berdasarkan hasil wawancara yang dilakukan dengan guru kelas II di SD Islam AI-Fattah Semarang, Ibu Ma'rifatun. Peneliti melakukan tanya jawab tentang kesulitan dan masalahmasalah yang ada pada saat proses pembelajaran. Dari hasil wawancara peneliti menemukan beberapa mata pelajaran yang dirasa sulit oleh siswa, namun peneliti memfokuskan pada satu mata pelajaran yaitu mata pelajaran matematika, dengan rendahnya hasil belajar siswa pada mata pelajaran matematika dimana masih ada peserta didik yang nilainya masih dibawah KKM. Dari hasil wawancara dengan guru, dibawah ini adalah nilai UTS matematika siswa, masih banyak nilai yang dibawah KKM. Sedangkan KKM yang ditetapkan sendiri 60, jadi dapat disimpulkan nilai matematika kelas II SD Islam Al Fattah Semarang masih banyak yang dibawah KKM. 
Tabel 1. Daftar Nilai Siswa

\begin{tabular}{lc}
\hline Nilai & Siswa \\
\hline $95-90$ & 1 \\
$90-85$ & 1 \\
$85-70$ & 2 \\
$75-65$ & 2 \\
$65-55$ & 7 \\
$55-40$ & 5 \\
$40-30$ & 2 \\
\hline & $\mathbf{2 0}$ \\
\hline
\end{tabular}

Hal yang membuat hasil belajar siswa kelas II SD Islam Al Fattah Semarang yaitu guru terlalu konvensional pada saat penyampaian materi pembelajaran, dalam proses pembelajaran juga masih menggunakan LKS sebagai acuan, dan juga masih menggunakan metode ceramah. Sehingga siswa kurang begitu paham mengenai materi terebut. Disini peneliti akan mengadakan penelitian dengan menggunakan model pembelajaran Make a match guna meningkatkan hasil belajar matematika SD Islam AI Fattah Semarang. Berdasarkan masalah di atas peneliti mengadakan penelitian dengan judul "Keefektifan model tipe Make a match terhadap hasil belajar matematika kelas II SD Islam AI Fattah Semarang".

Penerapan model Make a match dapat meningkatkan hasil belajar siswa. Hal ini dilihat pada proses pembelajaran didalam kelas guru membagikan kartu soal dan jawaban, cara pembelajaran dimana setiap siswa memegang kartu soal atau jawaban dan siswa dituntun untuk bekerjasama dengan siswa lain dalam menemukan kartu jawaban maupun kartu soal yang dipegang pasangannya dengan batas waktu tertentu, sehingga membuat siswa berfikir dan menumbuhkan semangat kerjasama, Suprijono (2012 : 94). Menurut Deschuri (2016) Dalam teknik make a match ini siswa akan diberikan kartu klop yang berisi konsep, materi maupun gambar. Mereka akan mencari dan mencocokan kartu gambar dan kartu penjelasan yang mereka pegang. Dalam proses inilah terjadi interaksi antar kelompok dan interaksi antar siswa di dalam kelompok untuk membahas kartukartu yang mereka pegang. Menurut Pista (2016) Make a match merupakan salah satu pembelajaran kooperatif yang dikembangkan oleh Lena Curran dengan teknik mencari pasangan sambil belajar mengenai konsep dalam suasana menyenangkan. Model pembelajaran make a match ini mengutamakan penanaman kemampuan bekerja sama, kemampuan berinteraksi dan kemampuan berpikir melalui permainan mencari pasangan dengan kartu bergambar.

Dengan menerapkan model pembelajaran Make a match pada proses pembelajaran dapat meningkatkan hasil belajar siswa. Hal tersebut dikarenakan dalam proses pembelajaran siswa memperhatikan dengan sangat baik dan siswa sangat antusias. Dapat diketahui bahwa hasil belajar siswa sangat baik. Penelitian ini menunjukan bahwa kelompok siswa yang dibelajarkan dengan menggunakan model pembelajaran Make a match lebih baik dibandingkan kelompok siswa yang dibelajarkan dengan menggunakan model yang belum variatif.

Selain model pembelajaran yang diterapkan, pembelajaran juga menggunakan media agar menarik perhatian siswa untuk mengikuti pembelajaran dan menyenangkan, yaitu dengan menggunakan media notasi waktu.

\section{Metode}

Jenis penelitian ini adalah Pre-Experimental Design dengan jenis One Group Pretestposttest Design. karena pada penelitian ini hanya menggunakan satu kelas saja dan agar hasilnya lebih akurat. Desain ini membandingkan keadaan sebelum diberi perlakuan dan sesudah diberi perlakuan.

Sugiyono (2017: 117) Populasi adalah wilayah generalisasi yang terdiri atas obyek/subyek yang mempunyai kualitas dan karakteristik tertentu yang ditetapkan oleh peneliti 
untuk dipelajari dan kemudian ditarik kesimpulannya. Populasi bukan hanya orang, tetapi juga obyek dan benda-benda alam yang lain. Populasi juga bukan sekedar jumlah yang ada pada obyek/subyek yang dipelajari, tetapi meliputi seluruh karakteristik/sifat yang dimiliki oleh subyek atau obyek itu, desain ini digambarkan sebagai berikut:

$$
O_{1} \rightarrow X \rightarrow O_{2}
$$

Keterangan :

$\mathrm{O}_{1}$ : Nilai pretest (sebelum diberi diklat)

$\mathrm{O}_{2}$ : Nilai posttest (setelah diberi diklat)

Jadi, populasi dapat diartikan sebagai jumlah keseluruhan dari subyek atau obyek tersebut. Dalam hal ini, populasi untuk penelitian ini adalah siswa-siswi kelas II SD Islam Al Fattah Semarang tahun pelajaran 2018/2019 yang berjumlah 20 siswa, yang terdiri dari 8 siswa perempuan dan 12 siswa laki laki.

Sugiyono (2017: 118) "sampel adalah bagian dari jumlah dan karakteristik yang dimiliki oleh populasi tersebut." Sampel dalam penelitian ini adalah seluruh kelas II SD Islam AI-Fattah Semarang yang berjumlah 20 siswa.

Sugiyono (2017: 119) "teknik sampling merupakan teknik pengambilan sampel untuk menentukan sampel yang akan digunakan dalam penelitian. Pada dasarnya teknik sampling dikelompokkan menjadi dua yaitu Probability Sampling dan Nonprobability Sampling." Penelitian ini menggunakan teknik Nonprobability Sampling karena semua anggota populasi dipilih menjadi sampel.

Teknik yang digunakan untuk menggumpulkan data dalam penelitian ini adalah a) Tes dalam penenelitian ini menggunakan tes obyektif pilihan ganda yang berjumlah 25 soal dan disusun berdasarkan indikator pencapaian dari materi pembelajaran. Tes diberikan sebelum perlakuan dan sesudah diberikan perlakuan. Jawaban bernilai satu (1) jika benar dan bernilai nol (0) jika salah. b) Observasi untuk penelitian ini dilaksanakan untuk mengetahui tingkat keaktifan siswa sebelum diberikan perlakuan dan sesudah diberikan perlakuan berdasarkan indikator yang telah disusun. c) Dokumentasi Pada penelitian ini teknik dokumentasi yang digunakan untuk mendapatkan data yang berupa daftar nama siswa dan daftar nilai KKM kelas II SD Islam Al Fattah Semarang.

Instrumen penelitian : a) Menentukan materi, Materi yang digunakan dalam penelitian ini yaitu satuan baku pengukuran waktu yang diajarkan pada siswa kelas II SD Islam AI Fattah Semarang. b) Menyusun kisi- kisi, Penyusunan kisi- kisi bertujuan agar soal yang telah disusun tidak menyimpang dari materi yang berpedoman dengan silabus dan materi pembelajaran Matematika tentang satuan baku pengukuran waktu. b) Menentukan tipe tes, Menentukan tipe soal yaitu pilihan ganda, isian, uraian, lisan dan sebagainya.Tipe soal yang digunakan dalam penelitian ini adalah tes yang berbentuk pilihan ganda. b) Menentukan Jumlah Soal, Jumlah soal yang akan digunakan dalam uji coba yaitu sebanyak 30 butir soal. Hal ini dilakukan agar tidak terjadi terjadi kekurangan soal ketika penganalisisan validitas, realibilitas, daya pembeda dan tingkat kesukaran soal. c) Pelaksanaan Tes Uji Coba, Setelah perangkat tes tersusun, kemudian diuji cobakan di SD yang bereda dengan sampel. Tes uji coba dilaksanakan pada semester genap tahun pelajaran 2018/2019 untuk menyiapkan butir- butir soal yang memenuhi kualifikasi soal yang layak digunakan.

Penganalisisan uji coba ini dilakukan dengan cara mengukur dan menghitung validitas, realibilitas, daya pembeda dan tingkat kesukaran soal. Secara umum dapat diuraikan sebagai berikut:

1) Uji validitas adalah suatu derajat ketetapan instrumen (alat ukur), maksudnya apakah instrumen yang digunakan betul-betul tepat untuk mengukur apa yang akan diukur (Arifin, 2014: 245). Untuk mengukur validitas, digunakan rumus korelasi product moment dengan angka kasar sebagai berikut: 


$$
r x y=\frac{N \sum X Y-\left(\sum X\right)\left(\sum Y\right)}{\sqrt{\left.\left\{N \sum X^{2}-\left(\sum X\right)^{2}\right\} N \sum Y^{2}-\left(\sum Y\right)^{2}\right\}}}
$$

(Arikunto, 2013: 87)

Keterangan:

$\mathrm{N} \quad=$ Jumlah subjek

$\Sigma X \quad=$ Jumlah Skor item

$\Sigma Y=$ Jumlah Skor Total

$\Sigma X Y=$ Jumlah Perkalian antara skor item dan skor total

$\Sigma X^{2} \quad=$ Jumlah skor item kuadrat

$\Sigma Y^{2} \quad=$ Jumlah skor total kuadrat

$\mathrm{r}_{\mathrm{xy}} \quad=$ Jumlah Skor Total Kuadrat

Soal yang baik adalah soal yang tidak terlalu mudah ataupuntidak terlalu sukar (Arikunto, 2013: 222). Bilangan yang menunjukan sukar dan mudahnya sbuah soal disebut indeks kesukaran $(P)$. Besarnya indeks kesukaran antara 0,00 sampai dengan 1,0. Untuk mencari indeks kesukaran, dapat menggunakan rumus yaitu:

$$
\mathrm{P}=\frac{B}{J S}
$$

(Arikunto, 2013: 223-225)

Keterangan:

$\mathrm{P}$ = indeks kesukaran

$\mathrm{B}$ = banyaknya siswa yang menjawab soal itu dengan betul

$\mathrm{JS}=$ jumlah seluruh siswa peserta tes

Klasifikasi indeks kesukaran yaitu:

$P=0,00-0,30=$ soal sukar

$P=0,31-0,70=$ soal sedang

$P=0,71-1,00=$ soal mudah

Instrumen dikatakan valid jika $r_{x y} \geq r_{\text {tabel }}$ jika $r_{x y}<r_{\text {tabel }}$ maka instrumen dikatakan tidak valid.

Tabel 2. Validitas Soal Uji Coba

\begin{tabular}{cccc}
\hline Kriteria & \multicolumn{1}{c}{ Nomor Soal } & Jumlah \\
\hline Valid & $1,2,3,5,6,7,8,9,10,11,14,15,16,18,19,21,22,23,24,25,26,27,28,29,30$ & 25 \\
Tidak Valid & $4,12,13,1720$ & Jumlah Soal & 5 \\
\hline & & J0 \\
\hline
\end{tabular}

2) Uji reliabilitas artinya dapat dipercaya atau dapat diandalkan. Sebuah tes dikatan reliable jika tes tersebut dapat memberikan hasil 'tetap' atau 'ajeg', artinya apabila tes tersebut diberikan pada sejumlah subjek, kemudian diberikan lagi pada subyek yang sama dilain waktu hasilnya relatif sama atau tetap. Untuk mencari reliabilitas soal maka digunakan rumus:

$$
r_{11}=\left(\frac{n}{n-1}\right) X\left(\frac{S^{2}-\sum p q}{S^{2}}\right)
$$

(Arikunto, 2013: 115) 
Keterangan:

$r_{11}=$ Realibilitas tes secara keseluruhan

$\mathrm{p}=$ Proporsi subjek yang menjawab item dengan benar

$q=$ Proporsi subjek yang menjawab item dengan salah

$(q=1-p)$

$\sum p q=$ Jumlah hasil perkalian antara $\mathrm{p}$ dan $\mathrm{q}$

$\mathrm{n}$ = banyaknya item

$\mathrm{s}=$ Standar deviasi dari tes

Harga $r_{11}$ dibandingkan dengan $\mathrm{r}_{\text {tabel }}$ Product Moment. Apabila jika $\mathrm{r}_{\text {hitung }}<\mathrm{r}_{\text {tabel }}$ maka instrumen tersebut reliabel atau dapat dipercaya. Klasifikasi Reliabilitas:

1) Antara $0,800-1,00=$ Realibilitas Sangat Tinggi

2) Antara 0,600 sampai dengan $0,800=$ Realibilitas tinggi

3) Antara 0,400 sampai dengan $0,600=$ Realibilitas cukup

4) Antara 0,200 sampai dengan $0,400=$ Realibilitas rendah

5) Antara 0,00 sampai dengan 0,200 = Realibilitas Sangat Rendah

Tabel 3. Analisis Reliabilitas Butir Soal

\begin{tabular}{ll}
\hline \multicolumn{1}{c}{ Nomor Soal } & Keterangan \\
\hline $1,2,3,4,5,6,7,8,9,10,11,12,13,14,15,16,17,18,19,20,21,22,23$, & Reliabilitas \\
$24,25,26,27,28,29,30$ & \\
\hline
\end{tabular}

3) Daya pembeda, Arikunto (2013: 26), daya pembeda soal adalah kemamapuan soal untuk membedakan antara siswa yang pandai (berkemampuan tinggi) dengan siswa yang bodoh (berkemampuan rendah). Angka yang menunjukkan daya pembeda disebut indeks diskriminasi (D). Cara menentukan daya pembeda soal, dapat dilakukan dengan membagi kelompok testee menjadi dua sama besar yaitu 50\% kelompok atas dan 50\% kelompok bawah. Rumus untuk menentukan indeks diskriminasi adalah:

$$
\mathrm{D}=\frac{B_{A}}{J_{A}}-\frac{B_{B}}{J_{B}}=P_{A}-P_{B}
$$

(Arikunto, 2013:223-225)

Keterangan:

$\mathrm{P}=$ indeks kesukaran

$\mathrm{B}$ = banyaknya siswa yang menjawab soal itu dengan betul

$\mathrm{JS}=$ jumlah seluruh siswa peserta tes

Klasifikasi indeks kesukaran yaitu:

$P=0,00-0,30=$ soal sukar

$P=0,31-0,70=$ soal sedang

$P=0,71-1,00=$ soal mudah

Berdasarkan hasil analisis instrumen uji coba, daya pembeda yang diperoleh dari hasil perhitungan sebagai berikut: Pada perhitungan taraf kesukaran instrumen soal uji coba, dapat diketahui 1 soal yang tergolong soal sukar yaitu nomor 20 , soal nomor $2,7,10,19,26,28$ tergolong soal yang sedang, sedangkan soal nomor $1,3,4,5,6,8,9,11,12,13,14,15,16,17,18,21,22,23,24,25,27,29,30$ tergolong soal dalam kategori mudah. 


\section{Hasil Dan Pembahasan}

Pada bagian ini yang akan dibahas adalah hasil penelitian dan pembahasan penelitian. Data tentang hasil belajar Matematika pada materi pengukuran baku satuan waktu yang diperoleh kemudian dianalisis dengan uji hipotesis. Sebelumnya data harus lolos pada uji prasyarat yaitu uji normalitas. Hasil uji normalitas pretest diperoleh $L_{0} 0,148$ dan $L_{\text {tabel }} 0,190$ dengan taraf signifikan $5 \%$ karena itu maka $H_{0}$ ditolak, jadi pretest berdistribusi normal. Sedangkan hasil uji normalitas posttest diperoleh $L_{0} 0,138$ dan $L_{\text {tabel }} 0,190$ dengan taraf signifikan $5 \%$ karena itu maka $H_{0}$ ditolak, jadi posttest berdistribusi normal .

Setelah data dinyatakan lolos uji prasyarat, maka dilanjutkan dengan analisis data. Analisis yang digunakan yaitu uji t. Berdasarkan hasil perhitungan yang telah diperoleh maka didapat $t_{\text {hitung }} 3,876$ dan $t_{\text {tabel }} 2,930$. Setelah nilai $t_{\text {hitung }}$ dan $t_{\text {tabel }}$ diketahui selanjutnya kedua nilai tersebut dibandingkan. Dapat diketahui bahwa ( 3,876>2,930). Hal ini berarti bahwa Ho ditolak dan Ha diterima. Jadi terdapat perbedaan yang signifikan antara nilai pretest dan posttest.

Tabel 4. Perbedaan Yang Signifikan Antara Nilai Pretest Dan Posttest

\begin{tabular}{lcccccc}
\hline \multicolumn{1}{c}{ Kelompok } & $\mathbf{N}$ & $\mathbf{M d}$ & $\bar{x}$ & $\mathbf{N}(\mathbf{n}-\mathbf{1})$ & $t_{\text {hitung }}$ & $t_{\text {tabel }}$ \\
\hline Pretest & 20 & \multirow{2}{*}{3,40} & 1340 & \multirow{2}{*}{380} & \multirow{2}{*}{3,876} & 2,930 \\
Posttest & 20 & & 1408 & &
\end{tabular}

Analisis dari hasil penelitian bahwa nilai rata-rata nilai pretest dapat mencapai 22,47 sedang nilai rata-rata posttest dapat mencapai 96,2. Dengan demikian hasil belajar Matematika lebih besar posttest dibandingkan dengan hasil belajar pretest. Untuk menghitung uji normalitas dan uji t di bantu oleh Microsoft excel, sedangkan taraf signifikan 5\% didapat dari $t_{\text {hitung }}$ dan $t_{\text {tabel }}$ karena $t_{\text {hitung }}>t_{\text {tabel }}$ maka Ho ditolak dan Ha diterima. Sehingga hasil tersebut menunjukkan bahwa model ada perbedaan antara hasil belajar pretest dengan hasil belajar posttest.

Adapun kelebihan dari model tipe Make a Macth menurut Huda (2015: 252) yaitu: dapat meningkatkan aktivitas belajar siswa, motode menyenangkan karena ada permainan, meningkatkan pemahaman siswa terhadap materi, meningkatkan motivasi belajar siswa, dan efektif sebagai sarana melatih keberanian siswa.

Hasil penelitian yang mendukung oleh I Kd Adi Wiguna, dkk (2014) volume 2 no. 1 tahun 2014, yang berjudul "Pengaruh Model Pembelajaran Kooperative Tipe Make a match Terhadap Hasil Belajar Matematika Siswa Kelas IV Di Gugus III Kecamatan Rendang" menunjukkan bahwa model pembelajaran Make a match berpengaruh terhadap hasil belajar matematika siswa kelas IV. Hal ini dibuktikan dengan rata-rata yang diperoleh kelas eksperimen yaitu 24,36 sedangkan rata-rata yang diperoleh kelas kontrol yaitu 21,06 .

Dari penelitian di atas menunjukkan model pembelajaran (Make a match) sangat berpengaruh terhadap hasil belajar siswa. Sehubungan dengan hal tersebut maka perlu dikembangkan penelitian-penelitian yang dapat meningkatkan hasil belajar siswa. Oleh karena itu penulis merasa perlu untuk mengadakan penelitian dengan judul "Keefektifan Model Tipe Make a match terhadap Hasil Belajar Matimatika Kelas II SD Islam AI Fattah Semarang".

\section{Simpulan dan Saran}

Model Make a match efektif terhadap hasil belajar matematika siswa kelas II SD Islam AI Fattah Semarang. Kriteria kefektifan tersebut adalah: dari hasil uji t menunjukkan bahwa $t_{\text {hitung }}>t_{\text {tabel }}(3,876>2,093)$ maka $H_{0}$ ditolak sehingga dapat disimpulkan ada perbedaan signifikan antara pretest dan posttest dengan menggunakan model Make a match terhadap hasil belajar matematika siswa kelas II SD Islam AI Fattah Semarang. 


\section{Daftar Rujukan}

Aliputri, Dhestha Hazilla. 2018. Penerapan Model Pembelajaran Kooperatif Tipe Make A Match Berbantuan Kartu Bergambar Untuk Meningkatkan Hasil Belajar Siswa. Jurnal Bidang Pendidikan Dasar (JBPD), Vol.2 No. 1A Hal. 70-77. Tersedia Pada : http://ejournal.unikama.ac.id/index.php/JBPD/article/view/2351.

Arikunto, Suharsini. 2006. Prosedur Penelitian Suatu Pendekatan Praktik. Jakarta: PT. Rineka Cipta.

Deschuri, Cani, Dadang Kurnia, Diah Gusrayani. 2016. Penerapan Model Kooperatif Teknik Make A Match dengan Media Kartu Klop uMeningkatkan Hasil Belajar Siswa pada Materi Kenampakan Alam dan Buatan. Jurnal Pena IImiah: Vol. 1, No. 1 Hal. 361-370. Tersedia Pada : http://ejournal.upi.edu/index.php/penailmiah/article/view/3042.

Hamzah, Ali dan Muhlisrarini. 2014. Perencanaan dan Strategi Pembelajaran Matematika.

Huda, Miftahul. 2013. Model-model Pengajaran dan Pembelajaran. Yogyakarta: Pustaka Pelajar.

Kurniasih dan Berlin. 2017. Ragam Pengembangan Model Pembelajaran, Jakarta: Kata Pena.

Muslimah, Kasmudin Mustapa, Ratman.2018. Penerapan Model Pembelajaran Kooperatif Tipe Make A Match untuk Meningkatkan Hasil Belajar Siswa pada Materi Larutan Elektrolit dan Non Elekrolit di Kelas X Madrasah Aliya DDI Lonja. J. Akademika Kim. Vol. 7 No. $1 \mathrm{Hal}$. 23-27. Tersedia Pada http://jurnal.untad.ac.id/jurnal/index.php/JAK/article/view/10386.

Sugiyono. 2017. Metode Penelitian Pendidikan. Bandung: Alfabeta.

Suprijono, Agus. 2015. Coorperative Learning. Yogyakarta: Pustaka Pelajar.

Undang - undang Republik Indonesia.

Wiguna, Adi. Dkk. 2014. "pengaruh model pembelajaran cooperative tipe make a match terhadap hasil belajar matematika siswa kelas IV di Gugus III Kecamatan Rendang" eJournal mimbar PGSD Universitas Pendidikan Ganesha jurusan PGSD (Vol. 2 No.1 Tahun 2014). 